This is an electronic reprint of the original article. This reprint may differ from the original in pagination and typographic detail.

Author(s): Dutton, Jason; Tuononen, Heikki; Jennings, Michael; Ragogna, Paul

Title: $\quad$ Extending the Series: Synthesis and Characterization of a Dicationic N-Heterocyclic Selenium Carbene Analogue

Year: $\quad 2006$

Version:

Please cite the original version:

Dutton, J., Tuononen, H., Jennings, M., \& Ragogna, P. (2006). Extending the Series: Synthesis and Characterization of a Dicationic N-Heterocyclic Selenium Carbene Analogue. Journal of the American Chemical Society, 128(39), 12624-12625. https://doi.org/10.1021/ja064381d

All material supplied via JYX is protected by copyright and other intellectual property rights, and duplication or sale of all or part of any of the repository collections is not permitted, except that material may be duplicated by you for your research use or educational purposes in electronic or print form. You must obtain permission for any other use. Electronic or print copies may not be offered, whether for sale or otherwise to anyone who is not an authorised user. 


\title{
Extending the Series: Synthesis and Characterization of a Dicationic N-heterocyclic Selenium Carbene Analogue
}

\author{
Jason L. Dutton, Heikki M. Tuononen†, Michael C. Jennings, and Paul J. Ragogna* \\ Department of Chemistry, University of Western Ontario, London, Ontario, N6A 5B7, Canada, and Department of \\ Chemistry, University of Jyväskylä, P.O. Box 35, FI-40014 Jyväskylä, Finland
}

pragogna@uwo.ca

The first report of a "bottleable" carbene by Arduengo et al. has had a significant impact on organic and inorganic chemistry. ${ }^{1}$ Since that time, there have been extensive efforts to isolate, comprehensively characterize and examine the reactivity of the isovalent p-block analogues, collectively known as "main group carbenoids". These compounds have been successfully synthesized for many of the p-block elements from Group 13 to 15 (Chart 1). ${ }^{2(a-n)}$ In each case, the main group element centre is two coordinate, electron rich (bears a "lone pair" of electrons) and can formally be anionic (Group 13), neutral (Group 14) or cationic (Group 15).

Chart 1. Known $\mathrm{N}$-heterocyclic $\mathrm{p}$-block carbenoids, and their unknown chalcogen analogues (boxed).

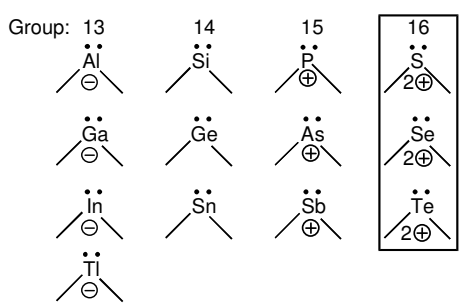

The change in formal charge at the central element has a profound impact on the spectroscopic properties and the reactivity of the carbenoid, in that they can range from being highly nuclelophilic (Group 13 and 14) to amphiphilic (Group 15), each with a vigorously developing chemistry. ${ }^{2(a), 3(a-e)}$

To extend the N-heterocyclic carbenoid series to Group 16 would necessitate the central element to formally carry a dicationic charge. These compounds are predicted to be extremely electrophilic, exhibit novel reactivity and are therefore, highly sought after synthetic targets. Any reports of such N-heterocyclic carbenoid bonding arrangements for the chalcogens have so far remained absent. ${ }^{4(\mathrm{a}-\mathrm{e})}$

In this context, we report the quantitative, room temperature synthesis and comprehensive characterization of a N-heterocyclic selenium "carbene" [1][SnCl6]." To our knowledge, this represents the first example of such a dicationic species in the classical NHC bonding arrangement and is a unique representative of a dicationic $\mathrm{Se}-\mathrm{N}$ heterocycle.

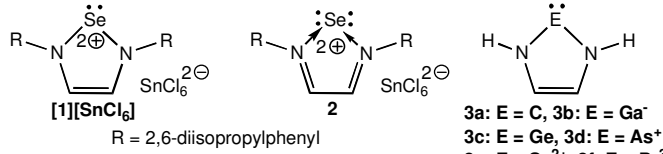

$$
\begin{aligned}
& \text { 3e: } E=\mathrm{Se}^{2+}, 3 \mathrm{ft}: \mathrm{E}=\mathrm{Br}^{3+}
\end{aligned}
$$

The reaction between a stoichiometric mixture of $\operatorname{Dipp}_{2} \mathrm{DAB}$ $\left(\right.$ Dipp $_{2} \mathrm{DAB}=1,4-(2,6$-diisopropyl)phenyl-1,4-diaza-1,3- butadiene) and $\mathrm{SnCl}_{2}$ with one equivalent of $\mathrm{SeCl}_{4}$ in $\mathrm{THF}$ solution at room temperature, results in the immediate formation of a red precipitate, which gradually $(30 \mathrm{~min}$.) dissolves to give a deep orange-red solution. Removal of the solvent in vacuo yields a deep orange-red powder. Proton NMR spectra of a sample of the redissolved powder in $\mathrm{CDCl}_{3}$ identified a remarkably pure product, with characteristic signals and consistent integration values for the Dipp $2 \mathrm{DAB}$ ligand. The most striking feature in the spectrum was a highly deshielded singlet $(\delta=10.58 \mathrm{ppm} ; 2 \mathrm{H})$ representing the backbone protons on the ligand framework. The chemical shift of these protons appears to be related to and distinctly diagnostic of the formal charge at the central atom (Table 1). Selenium-77 NMR spectra of the same sample revealed a single selenium signal $(\delta=1268 \mathrm{ppm})$. Single crystals of the material were grown from the bulk powder via vapor diffusion $\left(\mathrm{CH}_{2} \mathrm{Cl}_{2} / n\right.$-pentane), and X-ray diffraction studies of the crystalline sample identified the product to be the 2-coordinate, dicationic, N-heterocyclic selenium carbenoid [1][SnCl 6 (Figure $1)$.

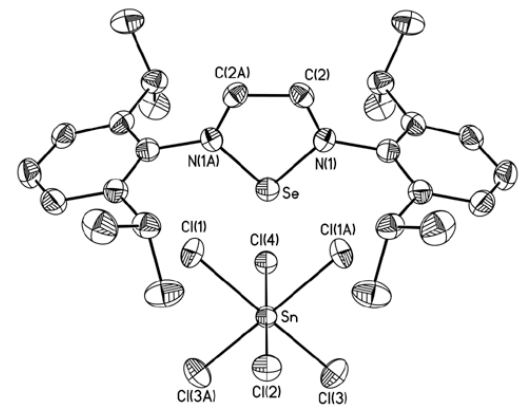

Figure 1. Solid-state structure of $[1]\left[\mathbf{S n C l}_{\mathbf{6}}\right]$. Ellipsoids are drawn to $50 \%$ probability, hydrogen atoms and $\mathrm{CH}_{2} \mathrm{Cl}_{2}$ solvate are removed for clarity. Selected bond lengths $(\AA)$ and angles $\left({ }^{\circ}\right)$ : Se-N(1) 1.890(4), N(1)$\mathrm{C}(2) \quad 1.293(7), \quad \mathrm{C}(2)-\mathrm{C}(2 \mathrm{~A}) \quad 1.415(10), \quad \mathrm{Sn}-\mathrm{Cl}(1) 2.496(2), \quad \mathrm{Sn}-\mathrm{Cl}(2)$ 2.393(2), Sn-Cl(3) 2.386(2), Sn-Cl(4) 2.415(2), $\mathrm{Se} \bullet \mathrm{Cl}(1)$ 2.742(2), $\mathrm{N}(1)-\mathrm{Se}-\mathrm{N}(1 \mathrm{~A}) \quad 81.8(3), \quad \mathrm{Cl}(2)-\mathrm{Sn}-\mathrm{Cl}(4) \quad 173.8(1), \quad \mathrm{Cl}(1)-\mathrm{Sn}-\mathrm{Cl}(3 \mathrm{~A})$ 93.0(1), $\mathrm{Cl}(3)-\mathrm{Sn}-\mathrm{Cl}(4)$ 91.4(1), $\mathrm{Cl}(3)-\mathrm{Sn}-\mathrm{Cl}(1)$ 179.2(1), $\mathrm{Cl}(2)-\mathrm{Sn}-$ $\mathrm{Cl}(1) 87.6(1), \mathrm{Cl}(4)-\mathrm{Sn}-\mathrm{Cl}(1)$ 88.0(1), $\mathrm{Cl}(2)-\mathrm{Sn}-\mathrm{Cl}(3)$ 93.0(1).

Although the precise mechanism for the quantitative formation of $[1]\left[\mathrm{SnCl}_{6}\right]$ is not yet known, the reaction likely proceeds through the reduction of $\mathrm{SeCl}_{4}$ by $\mathrm{SnCl}_{2}$. The resulting intermediate $\left[\mathrm{SeCl}_{2}\right]$ is sequestered by the $\mathrm{Dipp}_{2} \mathrm{DAB}$ ligand followed by an intramolecular 2-electron transfer from selenium to the energetically accessible LUMO of the ligand, with concomitant abstraction of the remaining two chlorides by $\mathrm{SnCl}_{4}$. This redox process is consistent with recent reports by Cowley $e t$ al. involving diimine ligands with $\mathrm{EX}_{3}(\mathrm{E}=\mathrm{P}, \mathrm{As} ; \mathrm{X}=\mathrm{Cl}, \mathrm{I}) .^{2(\mathrm{~b} ; \mathrm{c})}$

\footnotetext{
${ }^{\dagger}$ University of Jyväskylä
} 
Although compound [1][SnCl $\mathbf{6}]$ exhibits the expected bonding arrangement for a p-block carbenoid, there are several noteworthy features of the heterocycle. The endocyclic C-N bonds are shortened (1.293(7) $\AA$ ) and the C-C bond in the ligand backbone is elongated $(1.415(10) \AA$ ) with respect to related NHC's. Furthermore, the Se-N bond lengths are consistent with Se-N single bonds $(1.890(4) \AA)$, rather than that of an intermediate single or double Se-N bond, which is likely influenced by the close Se $\cdots$ Cl cation-anion contacts $(2.742(2) \AA$ ).

Table 1. Selected parameters for related Period 4, p-block carbenoids

\begin{tabular}{|c|c|c|c|c|}
\hline & E-N $N^{a}$ & $\mathrm{C}-\mathrm{N}^{a}$ & C-C $\mathrm{C}^{a}$ & $\delta^{b}$ \\
\hline $3 \mathbf{a}^{1}$ & $\begin{array}{c}1.358 \\
(1.366-1.373)\end{array}$ & $\begin{array}{c}1.383 \\
(1.382-1.386)\end{array}$ & $\begin{array}{c}1.349 \\
(1.338)\end{array}$ & 6.91 \\
\hline $3 \mathbf{b}^{2(\mathrm{f}, \mathrm{j}, \mathrm{k})}$ & $\begin{array}{c}1.983 \\
(1.983-1.985)\end{array}$ & $\begin{array}{c}1.379 \\
(1.367-1.423)\end{array}$ & $\begin{array}{c}1.358 \\
(1.347-1.380)\end{array}$ & $\begin{array}{r}6.13- \\
6.82\end{array}$ \\
\hline $3 \mathbf{c}^{2(\mathrm{i})}$ & $\begin{array}{c}1.871 \\
(1.856)\end{array}$ & $\begin{array}{c}1.371 \\
(1.384)\end{array}$ & $\begin{array}{c}1.354 \\
(1.364)\end{array}$ & 7.05 \\
\hline $3 \mathbf{d}^{2(a)}$ & $\begin{array}{c}1.810 \\
(1.809-1831)\end{array}$ & $\begin{array}{c}1.348 \\
(1.339-1.393)\end{array}$ & $\begin{array}{c}1.370 \\
(1.351-1.375)\end{array}$ & 8.22 \\
\hline$\left[1^{2+}\right]$ & $\begin{array}{l}1.870 \\
(1.890)\end{array}$ & $\begin{array}{l}1.321 \\
(1.293)\end{array}$ & $\begin{array}{l}1.400 \\
(1.415)\end{array}$ & 10.58 \\
\hline $3 e$ & 1.813 & 1.310 & 1.418 & -- \\
\hline 3f & 1.872 & 1.285 & 1.480 & -- \\
\hline
\end{tabular}

${ }^{a}$ Bond distances in ( $\AA$ ), experimental values in parenthesis; ${ }^{b}$ Experimental ${ }^{1} \mathrm{H}$ NMR chemical shifts (ppm) of the endocyclic C-C ring protons.

To garner a more complete understanding of the electronic structure of the heterocyclic ring [1][SnCl $\mathbf{6}$ ], we have performed a computational investigation of the title compound and for a model of the related p-block carbenoids (3a-f) ${ }^{\star}$ Results from the calculations for $\left[\mathbf{1}^{2+}\right]$ and 3a-f revealed metrical parameters in good agreement with those determined experimentally (Table 1). The computational studies for $\mathbf{3 e}$ indicate short endocyclic $\mathrm{C}-\mathrm{N}$ and long $\mathrm{C}-\mathrm{C}$ bonds relative to the parent $\mathrm{NHC}$ and related pblock carbenoids. A comparison of the frontier orbitals for the parent NHC and $\left[\mathbf{1}^{2+}\right]$ show little evidence for $\pi$-delocalization in the $\mathrm{N}-\mathrm{Se}-\mathrm{N}$ linkage in $\left.\mathbf{[ 1}^{2+}\right]$ and are reminiscent of single bonds (Figure 2). Consequently, this imposes enhanced multiple bond character in the endocyclic C-N linkage, while the endocyclic C-C bond is elongated. This phenomenon is even more apparent in the hypothetical brominenium trication (3f) where the endocyclic C$\mathrm{N}$ and $\mathrm{C}-\mathrm{C}$ bonds further shorten and elongate, respectively.

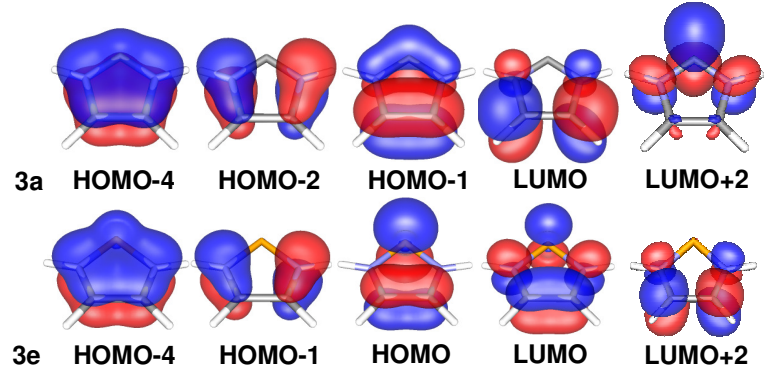

Figure 2. $\pi$-Symmetric frontier KS-orbitals of 3a and 3e.

Given these data, [1][SnCl6] may be considered as a $\mathrm{Se}^{2+}$ dication sequestered by a chelating diimine (2), rather than having undergone the intramolecular charge transfer as reported for the pnictogen $(\mathrm{Pn})$ analogues $(\mathrm{Pn}=\mathrm{P}, \mathrm{As}) .^{2(\mathrm{a}, \mathrm{b})}$ A sequestered $\mathrm{Se}^{2+}$ cation is reminiscent of the base stabilised, low oxidation state $\mathrm{P}(\mathrm{I})$ or As(I) cations. ${ }^{5 \mathrm{a} ; \mathrm{b}}$ The reduction process for the synthesis of $[1]\left[\mathrm{SnCl}_{6}\right]$ is related to that reported for the production of monocationic Se-N rings using neutral DAB ligands, however in this case, the Dipp $2 \mathrm{DAB}$ ligand remains resilient giving a $\mathrm{Se}-\mathrm{N}$ dication, as opposed to the loss of one alkyl substituent in the ${ }^{t} \mathrm{Bu}$ analogue, which results in the formation of monocationic Se-N rings. ${ }^{5 \mathrm{c}}$

The bonding model in $\mathbf{2}$ is supported by the topological analysis of the electron localization function, which shows two monosynaptic basins for $\mathrm{Se}$ in $[\mathbf{1}]\left[\mathbf{S n C l}_{\mathbf{6}}\right]$, indicating that selenium carries two "lone pairs" of electrons instead of the expected one. This is corroborated by the results from atoms-inmolecules and MO analyses which show two local maxima in the Laplacian of the electron density around the Se nucleus and the presence of two sigma-symmetric lone-pair type MOs on the Se atom, respectively. However, an understanding of the true nature of the selenium "carbenoid" will require a combination of structure and reactivity studies. We are currently investigating the Lewis acid/base properties of [1][SnCl $\mathbf{6}]$, including its propensity to form complexes with transition metals.

In summary, we have identified a simple, quantitative, room temperature synthesis of a dicationic N-heterocyclic selenium "carbenoid". This represents the first report of a chalcogenium dication mimicking the ubiquitous Arduengo-type carbene.

Acknowledgment. We thank the Natural Science and Engineering Research Council of Canada (NSERC), the Academy of Finland and the University of Western Ontario for their generous financial support.

(1) Arduengo, A. J. I.; Harlow, R. L; Kline, M. J. Am. Chem. Soc., 1991, 113, 361

(2) (a) Jones, C.; Junk, P. C.; Platts, J. A.; Stasch, A. J. Am. Chem. Soc. 2006; 128, 2206; (b) Reeske G.; Cowley, A. H. Chem. Commun. 2006, 1784; (c) Reeske, G.; Hoberg, C. R.; Hill, N. J.; Cowley, A. H. J. Am. Chem. Soc. 2006, 128, 2800; (d) Peng, Y.; Fan, H.; Zhu, H.; Roesky, H. W.; Magull, J.; Hughes, C. E. Angew Chem. Int. Ed. 2004, 43, 3443; (e) Jones, C.; Junk, P. C.; Platts, J. A.; Rathmann, D.; Stasch, A. Dalton Jones, C.; Junk, P. C.; Platts, J. A.; Rathmann, D.; Stasch, A. Dalton
Trans. 2005, 2497; (f) Hill, M. S.; Hitchcock, P. B. Chem. Commun. 2004, 1818; (g) Gans-Eichler, T.; Gudat, D.; Nieger, M. Angew. Chem. Int. Ed. 2002, 41, 1888; (h) Hardman, N. J.; Eichler, B. E.; Power, P. P. Chem. Commun. 2000, 1991; (i) Haaf, M.; Schmiedl, A.; Schmedake, T. A.; Powell, D. R.; Millevolte, A. J.; Denk, M.; West, R. J. Am. Chem. Soc. 1998, 120, 12714; (j) Carmalt, C. J.; Lomeli, V.; McBurnett, B. G.; Cowley, A. H. Chem. Commun. 1997, 2095; (k) Herrmann, A. W.; Denk, M.; Behm, J.; Scherer, W. Klingan, F.; Bock, H.; Solouki, B.; Wagner, M.; Behm, J.; Scherer, W.; Klingan, F.; Bock, H.; Solouki, B.; Wagner, Jockisch, A.; Schmidbaur, H. J. Am. Chem. Soc. 1999, 121, 9758; (m) Baker, R. J.; Farely, R. D.; Jones, C.; Kloth, M.; Murphy, D. M. J. Chem. Soc., Dalton Trans. 2002, 3844; (n) Denk, M.; Lennon, R.; Hayashi, R.; West, R.; Belyakov, A. V.; Verne, H. P.; Haaland, A.; Wagner, M.; Metzler, N. J. Am. Chem. Soc. 1994, 116, 2691.

(3) For representative examples, see: (a) Baker, R. J.; Jones, C.; Kloth, M. J. Chem. Soc., Dalton Trans. 2005, 2106; (b) Burford, N.; Herbert, D. E.; Ragogna, P. J.; McDonald, R.; Ferguson, M. J. J. Am. Chem. Soc. 2004, Ragogna, P. J.; McDonald, R.; Ferguson, M. J. J. Am. Chem. Soc. 2004,
126, 17067; (c) Yang, Z. ; Ma, X.; Oswald, R. B.; Roesky, H. W.; Baldus, M.; Schmidt, H.-G.; Noltemeyer, M.; Zhu, H.; Schulzke, C.; Starke, K. Angew. Chem. Int. Ed., 2005 117, 7234; (d) West, R.; Moser, D. F.; Guzei, I. A.; Lee, G-H.; Naka, A.; Li, W.; Zabula, A.; Bukalov, S.; Leites, L. Organometallics 2006, 11, 2709; (e) Hardman, N. J.; Abrams, M. B.; Pribisko, M. A.; Gilbert, T. M.; Martin, R. L., Kubas, G. J.; Baker, R. T. Angew. Chem. Int. Ed. 2005, 43, 1955

(4) There have been sporadic reports of base-stabilized (hypervalent) chalcogen dications. (a) Kobayashi, K.; Sato, S.; Horn, E.; Furukawa, N. Angew. Chem. Int. Ed. 2000, 39, 1318; (b) Fujihara, H.; Mima, H.; Furukawa, N. J. Am. Chem. Soc., 1995 117, 10153; (c) Fujihara, H.; Mima, H.; Erata, T.; Furukawa, N. J. Am. Chem. Soc. 1992, 114, 3117; (d) Awere, E. G. Passmore, J.; White, P. S.; Klapötke, T. J. Chem. Soc., Chem. Commun., 1989, 1415; (e) For a moncationic Se-N ring see Gieren, A.; Hübner, T.; Lamm, V.; Neidlein, R.; Droste, D. Z. Anorg. Allg. Chem. 1985, 523, 33 .

(5) (a) Ellis, B. D.; Dyker, C. A.; Decken, A.; Macdonald, C. L. B. Chem. Commun. 2005, 1965; (b) Ellis, B. D.; Carlesimo, M.; Macdonald, C. L. B. Chem. Commun. 2003, 1946; (c) Dutton, J. L., Tindale, J. J. Jennings, M. C., Ragogna, P. J. Chem. Commun. 2006, 2474. 